\title{
MINIMAL RECORDED EARTHQUAKES*
}

\author{
By C. F. Richter and J. M. NordQUisT
}

THE MAGNITUDE of an earthquake was originally defined (Richter, 1935) ${ }^{1}$ as the common logarithm of the maximum displacement, expressed in microns, of the trace written by a standard torsion seismometer at an epicentral distance of 100 kilometers. When this trace amplitude is one micron the magnitude is accordingly zero.

TABLE I

Data of Princtpal Shock, February 18, 1948

\begin{tabular}{|c|c|c|c|c|c|c|c|}
\hline \multirow{2}{*}{$\underset{(\mathrm{km} .)}{\Delta}$} & \multirow{2}{*}{ Station } & \multirow{2}{*}{ Wave } & \multirow{2}{*}{ Arrival time } & \multicolumn{2}{|c|}{ Amplitudes (mm.) } & \multicolumn{2}{|c|}{ Magnitude (corrected) } \\
\hline & & & & $\mathrm{N}$ & $E$ & $\mathrm{~N}$ & $\mathbf{E}$ \\
\hline 16 & Riverside. & $\begin{array}{l}\text { iP } \\
\text { is }\end{array}$ & $\begin{array}{ccr}\mathrm{h} & \mathrm{m} & \mathrm{s} \\
05 & 38 & 53.6 \\
& & 55.5\end{array}$ & 49 & 51 & 3.5 & 3.5 \\
\hline 55 & Mount Wilson.... & $\begin{array}{l}\text { iP } \\
\text { is }\end{array}$ & $\begin{array}{r}053900.0 \\
06.8\end{array}$ & 3.9 & 4.1 & 3.3 & 3.3 \\
\hline 60 & Pasadena........ & $\begin{array}{l}\text { iP } \\
\text { is }\end{array}$ & $\begin{array}{l}01.1 \\
08.6\end{array}$ & 1.4 & 1.1 & 3.2 & 3.1 \\
\hline 95 & Palomar...... & $\begin{array}{l}\text { iP } \\
\text { is }\end{array}$ & $\begin{array}{l}07.0 \\
18.6\end{array}$ & & & & \\
\hline 125 & La Jolla. & $\begin{array}{l}\text { iP } \\
\text { is }\end{array}$ & $\begin{array}{l}12.4 \\
28.2\end{array}$ & 1.8 & 1.5 & 3.5 & 3.3 \\
\hline 205 & Santa Barbara.... & iP & 24.2 & 0.7 & 0.7 & 3.3 & 3.3 \\
\hline 243 & Haiwee. . & $\mathrm{eP}$ & 27.2 & 0.2 & 0.2 & 3.1 & 3.1 \\
\hline 352 & Tinemaha.. & $\mathrm{eP}$ & 41.0 & 0.3 & 0.3 & 3.6 & 3.6 \\
\hline
\end{tabular}

This zero was arbitrarily chosen to fall slightly below the magnitude of the smallest recorded shocks, avoiding the inconvenience of negative magnitudes. Instances were given of small earthquakes near the Haiwee station with estimated magnitudes as low as 0.2 . The revised magnitude scale for short distances (table 3 of Gutenberg and Richter, 1942) ${ }^{2}$ would give 0.6 for the same shocks.

\footnotetext{
* Manuscript received for publication March 3, 1948.

1 C. F. Richter, "An Instrumental Earthquake Magnitude Scale," Bull. Seism. Soc. Am., 25: 1-32 (1935).

${ }^{2}$ B. Gutenberg and C. F. Richter, "Earthquake Magnitude, Intensity, Energy, and Acceleration," Bull. Seism. Soc. Am., 32: 164-191 (1942).
} 
Opportunities for such observations are infrequent. They call for a group of shocks from a single source close to a station, including some large enough to be recorded at other stations, located, and assigned magnitudes. Such a group occurred near Riverside, California, February 18-19, 1948. The largest of these was recorded at the times given in table 1 . (All times in this paper are Pacific Standard Time.)

TABLE 2

Trace Amplitudes of Shocks near Riverside, 1948. (In millimeters)

\begin{tabular}{|c|c|c|c|c|c|c|c|c|c|c|}
\hline \multirow{2}{*}{ Date } & \multirow{2}{*}{$\begin{array}{c}\text { Arrival } \\
\text { time }\end{array}$} & \multicolumn{3}{|c|}{ Pasadena } & \multicolumn{3}{|c|}{ Mount Wilson } & \multicolumn{3}{|c|}{ Riverside } \\
\hline & & $\mathrm{N}$ & $\mathrm{E}$ & $z$ & $\mathrm{~N}$ & $\mathbf{E}$ & $z$ & $\mathrm{~N}$ & $\mathrm{E}$ & $\mathrm{z}$ \\
\hline \multirow{3}{*}{ Feb. 18} & $\begin{array}{cl}\mathrm{h} & \mathrm{m} \\
05 & 38\end{array}$ & 1.4 & 1.1 & 34.0 & 3.9 & 4.1 & $71 ?$ & 49 & 51 & \\
\hline & $05 \quad 42$ & 0.2 & 0.3 & 2.9 & 0.6 & 0.8 & 13.8 & 8.8 & 6.7 & . \\
\hline & $03 \quad 55$ & 0.2 & 0.3 & 1.4 & 0.3 & 0.4 & 7.2 & 3.6 & 3.9 & $\ldots$ \\
\hline Feb. 19 & $04 \quad 28$ & 0.1 & 0.1 & 1.0 & 0.3 & 0.2 & 5.9 & 2.9 & 2.6 & $\ldots$ \\
\hline
\end{tabular}

TABLE 3

Trace Amplttude of Small Shocks near Riverside, 1948. (In millimeters)

\begin{tabular}{|c|c|c|c|c|c|}
\hline \multirow{2}{*}{ Date } & \multirow{2}{*}{$\begin{array}{c}\text { Arrival } \\
\text { time }\end{array}$} & \multirow{2}{*}{$\begin{array}{c}\text { Mount Wilson } \\
\mathrm{Z}\end{array}$} & \multicolumn{3}{|c|}{ Riverside } \\
\hline & & & $\mathrm{N}$ & $\mathrm{E}$ & $\mathrm{z}$ \\
\hline \multirow{6}{*}{ Feb. 18} & $\begin{array}{cr}\mathrm{h} & \mathrm{m} \\
04 & 00\end{array}$ & 0.9 & 0.7 & 0.6 & 8.7 \\
\hline & $05 \quad 37$ & 0.9 & 0.8 & 0.6 & 7.2 \\
\hline & $06 \quad 38$ & 1.3 & 1.1 & 0.8 & 9.7 \\
\hline & $\begin{array}{ll}06 & 40\end{array}$ & 0.7 & 0.6 & 0.8 & $3.8 ?$ \\
\hline & $07 \quad 10$ & 0.4 & 0.4 & 0.4 & 3.1 \\
\hline & $07 \quad 39$ & $?$ & 0.5 & 0.4 & 3.7 \\
\hline Feb. 19 & $02 \quad 59$ & 0.4 & 0.5 & 0.4 & 4.9 \\
\hline
\end{tabular}

These give an epicenter near $33^{\circ} 59^{\prime} \mathrm{N}, 117^{\circ} 33^{\prime} \mathrm{W}$, with origin time 05:38:50. Measured distances from this point are given in table 1 , which also includes the trace amplitudes in millimeters on the two standard torsion seismometers ( $\mathrm{N}$ and $\mathrm{E}$ at each station). The final columns give the magnitude of this shock calculated individually for each instrument, using table 1 of the 1935 paper and table 3 of the 1942 paper, with the ground factor corrections at each station given by Richter (1935) and slightly modified by Gutenberg (1943, p. 515)..$^{3}$ These give a mean magnitude of 3.34 ; since this is based on 14 independent observations, its standard error is about 0.04 .

${ }^{3}$ B. Gutenberg, "Earthquakes and Structures in Southern California," Bull. Geol. Soc. Am., 54: 499-526 (1943). 
Magnitudes of the other shocks can be derived by comparison of amplitudes. About one hundred of these can be found on the vertical component $(Z)$ seismograms written at Riverside, most of them in two groups about a day apart. They are identifiable by the interval of 1.9 seconds between the sharp $\mathrm{P}$ and $\mathrm{S}$ groups. Their occurrence at irregular hours, and their wide range of recorded amplitudes, show clearly that they are natural earthquakes. More-
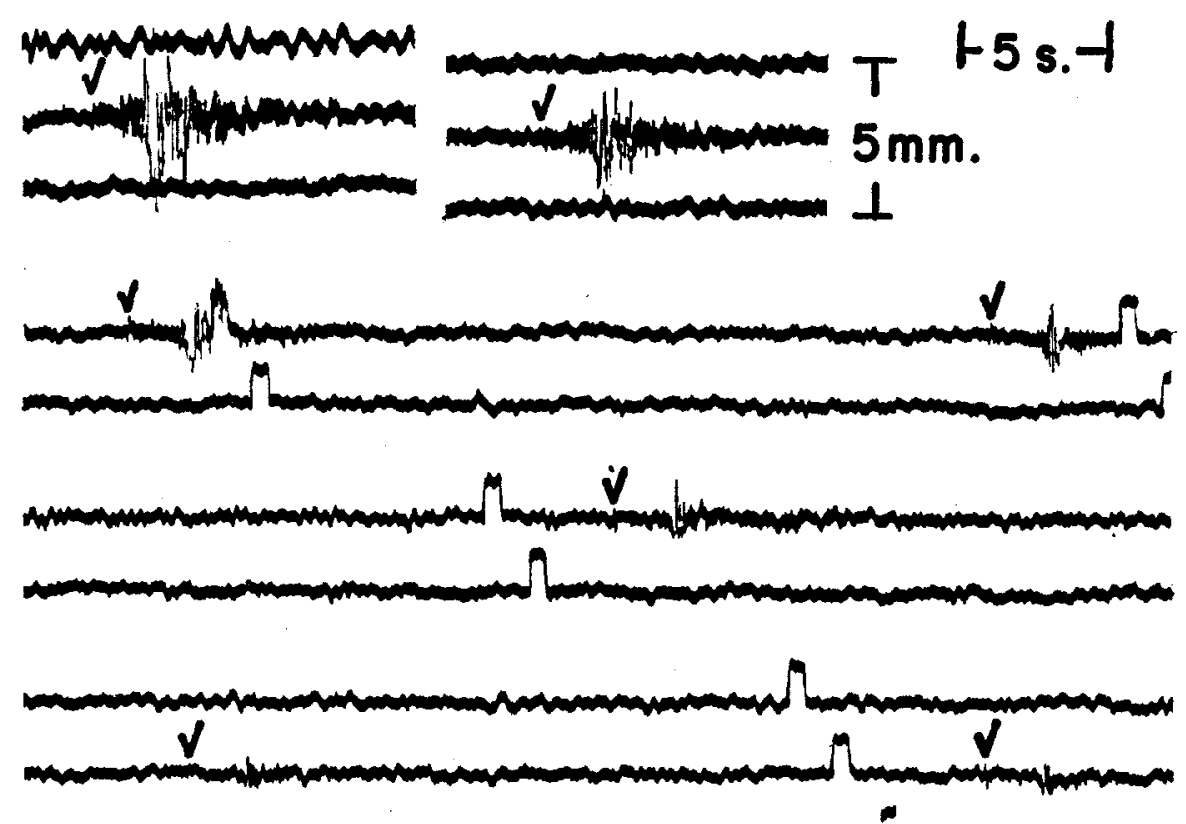

Fig. 1. Small earthquakes recorded at Riverside, California, February 18-19, 1948. Benioff short-period vertical-component seismometer. Enlarged. Original spacing between lines, $2 \frac{1}{2} \mathrm{~mm}$. Recording speed, $1 \mathrm{~mm} / \mathrm{sec}$. Check mark $(\checkmark)$ above $P$ of each shock.

over, the epicenter for the largest, determined from the data of table 1, is consistent with a focal depth the most likely value for which is 14 kilometers.

Trace amplitudes for some of the smaller shocks are given in tables 2 and 3. The columns headed $\mathrm{N}$ and $\mathrm{E}$ refer to the torsion seismometers; those headed $\mathrm{Z}$, to the Benioff vertical-component seismometers. The approximate constancy of the ratio between the amplitudes recorded for two selected shocks by the various instruments is evident. The smallest shock in these tables is that on February 18 at $07: 10$. Comparison of this with that at $06: 38$ and with the largest shock at 05:38 indicates a ratio of about 130 to 1 between the amplitudes of the largest and smallest. This implies a difference in magnitude of 2.11, which would give the shock at 07: 10 a magnitude of 1.23.

Still smaller shocks are found on the Riverside $Z$ records. They range down 
to maximum amplitudes barely exceeding the breadth of the recording line and obscured by the small background disturbance. They are, however, recognizable by close examination under a lens, both $\mathrm{P}$ and $\mathrm{S}$ being distinguishable. Figure 1 is an attempt to reproduce some of the small earthquake traces on an enlarged scale. The original spacing between recording lines was $2 \frac{1}{2}$ millimeters. The smallest identified amplitudes are between 0.3 and 0.4 millimeters, which by comparison with the shocks of table 3 yields a magnitude of 0.4 .

Table 4 shows the numbers of these shocks with given amplitudes from 0.4 to 3.2 millimeters found on the Riverside vertical-component seismograms for February 18-19. About 15 doubtfully identified shocks are omitted, mostly

TABLE 4

Statistics of Smatl Shocks, February 18-19, 1948

\begin{tabular}{|c|c|c|c|c|c|c|c|c|}
\hline$A=$ amplitude (units of & & & & & & & & \\
\hline $\begin{array}{r}0.1 \mathrm{~mm} .) \ldots \ldots \ldots \\
f=\text { number of shocks. }\end{array}$ & $3-4$ & $\begin{array}{l}56 \\
67\end{array}$ & $\begin{array}{l}78 \\
44\end{array}$ & $\begin{array}{rr}9 & 10 \\
12 & 5\end{array}$ & $\begin{array}{rr}11 & 12 \\
2 & 4\end{array}$ & $\begin{array}{rr}13 & 14 \\
3 & 3\end{array}$ & $\begin{array}{rr}15 & 16 \\
3 & 3\end{array}$ & $\begin{array}{rl}17 & 18 \\
2 & 1\end{array}$ \\
\hline$f$ smoothed.............. & 19 & 13 & 12 & 11.5 & 9.5 & 5.3 & 5.0 & 4.0 \\
\hline$Q=A f \ldots \ldots$ & 76 & 78 & 96 & 115 & 114 & 74 & 80 & 72 \\
\hline $\begin{array}{r}A=\text { amplitude (units of } \\
0.1 \mathrm{~mm} . \text {. . . . . }\end{array}$ & 1920 & 2122 & 2324 & 2526 & $27 \quad 28$ & 2930 & 3132 & \\
\hline$f=$ number of shocks. & 22 & 12 & 12 & 32 & 05 & 02 & 00 & \\
\hline$f$ smoothed.... & 3.3 & 3.3 & 2.8 & 3.5 & 4.3 & 3.0 & & \\
\hline$Q=A f \ldots \ldots \ldots \ldots$ & 66 & 73 & 67 & 91 & 120 & 90 & & \\
\hline
\end{tabular}

among the smallest amplitudes. The sums of successive pairs of entries have been smoothed; the results are given in the third line.

Previous study indicates that the frequency of shocks of all magnitudes increases about tenfold for a downward step of one magnitude unit, which would mean that the frequency of shocks varies inversely as the recorded amplitude at a fixed distance. Accordingly, the smoothed frequency numbers $f$ have been multiplied by the corresponding amplitudes $A$, giving the numbers $Q$ in the fourth line of table 4 . It will be seen that these show no systematic variation across the magnitude range, indicating that the numbers of earthquakes increase regularly down to at least magnitude 0.4 (corresponding to recorded amplitudes of $0.3-0.4 \mathrm{~mm}$.). It is physically impossible for this to continue indefinitely toward smaller magnitudes; at some point the minimum earthquake must be approached and the numbers decrease. Present observations apparently do not reach this critical level of magnitude.

An attempt may be made to calculate the energy radiated in the elastic waves of the minimal observed shock of magnitude 0.4 . The seismograms at the shortest distance show that the motion in the smallest shocks consists 
principally of a sharp $\mathrm{P}$ and a sharp $\mathrm{S}$, with periods of about 0.1 second or less, each phase appearing as about one complete wave. Table 3 indicates that an amplitude of about $0.4 \mathrm{~mm}$. on the Riverside vertical-component record should correspond to about $0.05 \mathrm{~mm}$. on the torsion seismometers. These seismometers have a free period of 0.8 second, so that the magnification is sensibly equal to the static magnification 2,800. This gives a true ground amplitude of 0.02 microns in each horizontal component. The epicenter is approximately west of Riverside, so that the north-south component should register chiefly the SH (polarized normal to the plane of propagation), and the east-west should have registered SV. The effect of the free surface is such that the amplitude of SH at the surface is doubled; that of SV is increased by a smaller factor. The true amplitude $\mathrm{A}$ within the earth may then be taken as about 0.01 microns.

The focal distance $r$ to Riverside is about $20 \mathrm{~km}$.; the density $d$ may be taken as $3 \mathrm{gm} / \mathrm{cc}$., and the velocity $v$ of $\mathrm{S}$ waves as $3 \mathrm{~km} / \mathrm{sec}$. Then the total kinetic energy in a spherical shell of the thickness of one wave length (which agrees with the observation that the recorded $\mathbf{S}$ consists apparently of one full wave) with the given radius, and period $T=0.1$ second, is

$$
K E=4 \pi^{3} r^{2} A^{2} v d / T=4 \times 10^{11} \mathrm{ergs} .
$$

The energy radiated in the shock must be taken as 4 times this quantity, since approximately equal energies are radiated in $\mathrm{P}$ and $\mathrm{S}$ waves, and the mean potential energy in the wave shell equals the mean kinetic energy $K E$.

This gives $2 \times 10^{12}$ ergs for the energy of a shock of magnitude 0.4 .

In current calculations we are using the formula

$$
\log E=12+1.8 M
$$

which would give about $5 \times 10^{12} \mathrm{ergs}$.

Summary.-Small earthquakes near Riverside have been identified with magnitudes as low as 0.4 . The corresponding energy is of the order of $10^{12}$ ergs. The number of shocks increases regularly with decreasing magnitude.

Note added in proof.-On June 16, 1948, beginning at 16:53, a series of small shocks occurred close to the Haiwee station. The same methods as used in this paper give a range of magnitude from 3.4 down to 0.0 .

California Institute of Technology,

Pasadena, California

(Balch Graduate School of the Geological Sciences, Contribution No. 447). 